\title{
A tilt and roll device for automated correction of rotational setup errors
}

\author{
David C. Hornick, Dale W. Litzenberg, Kwok L. Lam, James M. Balter, Joel Hetrick, \\ and Randall K. Ten Haken \\ Department of Radiation Oncology, University of Michigan, Ann Arbor, Michigan 48109-0010
}

(Received 20 March 1998; accepted for publication 1 July 1998)

\begin{abstract}
A tilt and roll device has been developed to add two additional degrees of freedom to an existing treatment table. This device allows computer-controlled rotational motion about the inferiorsuperior and left-right patient axes. The tilt and roll device comprises three supports between the tabletop and base. An automotive type universal joint welded to the end of a steel pipe supports the center of the table. Two computer-controlled linear electric actuators utilizing high accuracy stepping motors support the foot of table and control the tilt and roll of the tabletop. The current system meets or exceeds all pre-design specifications for precision, weight capacity, rigidity, and range of motion. (C) 1998 American Association of Physicists in Medicine. [S0094-2405(98)01909-9]
\end{abstract}

Key words: computer-controlled, patient setup

Accurate daily localization of treatment fields relative to patient anatomy can greatly reduce inherent uncertainties in the treatment process. ${ }^{1}$ The feasibility of daily localization checks now exists due to the advent of high quality portal imaging devices, digital imaging systems, and image registration software. ${ }^{2-4}$ Computer-controlled setup corrections ${ }^{5}$ followed by real-time compensation for organ motion during treatment ${ }^{6}$ promise to significantly extend this process.

Currently, treatment tables provide four degrees of freedom comprising three linear translations along the orthogonal axes and rotation only about the vertical axis. This arrangement precludes direct correction for patient rotational setup errors about the remaining two horizontal axes using only the treatment table. Although gantry and collimator rotation can provide the additional two degrees of freedom necessary to compensate for such patient setup changes, their use in conjunction with the table can lead to major changes in machine geometry for small rotational corrections. For example, assume a supine patient with anterior-posterior (AP) and lateral beam ports that inadvertently sets up tilted, with the head end slightly too high and foot end slightly too low. Correction for this setup error for the lateral beam requires only a slight rotation of the collimator to match the patient tilt. However, correct placement of the AP beam would require rotation of the table by $90^{\circ}$, followed by gantry rotation toward the patients feet corresponding to the tilt angle, followed by rotation of the collimator by $90^{\circ}$ to realign the block outline. Adding two additional degrees of freedom directly to the treatment table ${ }^{7}$ allows all patient setup changes but avoids these complicated, wide ranging movements.

We chose to address this issue through the design and construction of an ancillary system for an existing patient treatment table that added tilt (rotation about the cross table axes) and roll (rotation about the table's long axis). Required features of the Tilt and Roll system (TARS) included: angular motion over an acceptable range, a minimum of additional mechanical deflections in the table assembly, additional size and weight consistent with an acceptable range of vertical motion, and overall patient weight capacity, and computer control.

In order to compensate for the majority of reported rotational setup errors, ${ }^{4,8}$ we specified that the table reach $\pm 3^{\circ}$ in both tilt and roll simultaneously. Consistent with the premodification values, we specified the maintenance of an overall load capability of $160 \mathrm{~kg}$ with the tabletop fully extended toward the gantry, and a minimum safety factor of 3 under maximum load capacity for all new components. We targeted an overall accuracy of $\pm 0.1^{\circ}$ with a repeatability of $\pm 0.05^{\circ}$.

Our solution uses a three-point support system located between the tabletop and the table base assembly. Attachment of a modified automotive type universal joint under the middle of the tabletop and two linear actuators (Industrial Devices Corporation, $N$ series) under the corners of one end of the tabletop provides the necessary support (Figs. 1, 2). The universal joint allows the tabletop to tilt about its lateral axis and roll about its longitudinal axis while eliminating rotational motion about the axis perpendicular to the tabletop. Fixed pivot points result from using spherical rod ends to mount the ends of the actuators to both the table pedestal and tabletop. The actuators operate in tension during normal

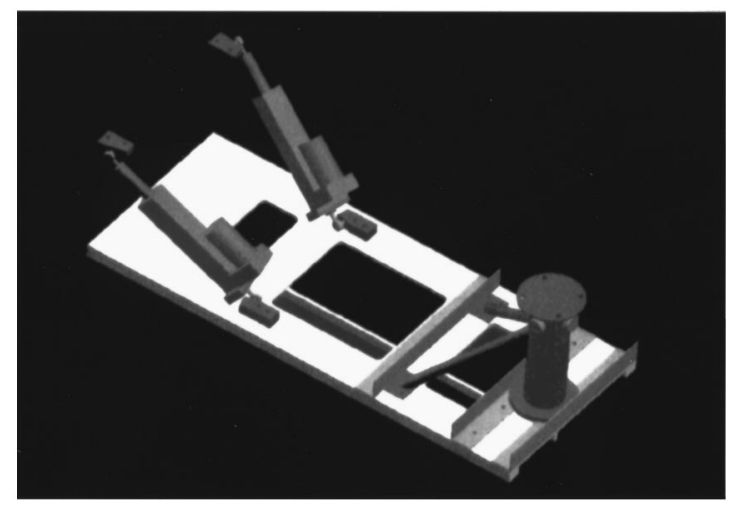

FIG. 1. Computer generated model of tilt and roll system. 


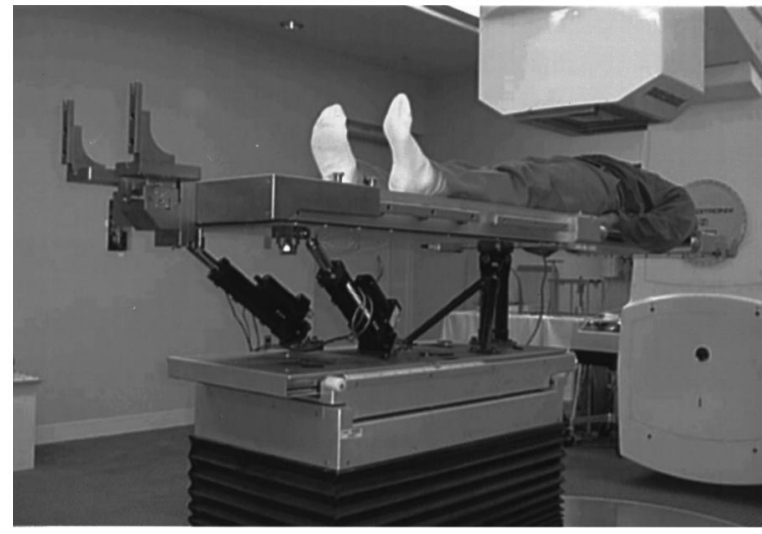

FIG. 2. Tilt and roll system under load.

extended table treatments and in compression should the table be reversed (e.g., for some head and neck treatments). Placement of the universal joint under the middle of the table minimized the moment arm for unwanted rotations about the vertical axis and reduced the load on the actuators. Mounting the actuators along radial lines from the universal joint further minimized unwanted torque about the vertical axis of the universal joint. Replacement of the standard needle bearings with custom made press-fit brass bushings reduced rotational play in the universal joint itself.

Repeatedly placing the table to seven different wellknown positions in tilt and in roll helped to quantify the angular repeatability of the system. Careful measurements using a very high precision bubble level together with a sine bar and precisely machined shims defined each position. After recording the actuator positions, a series of moves was initiated that set the table angle away from and then back to each position five times with approaches from different di-

TABLE I. Angular repeatability values for a treatment table tilt and roll device.

\begin{tabular}{|c|c|c|c|}
\hline \multicolumn{4}{|c|}{ Tilt data (inferior-superior) } \\
\hline Angle (degrees) & $\begin{array}{l}\text { Average actuator } \\
\text { position }(\mathrm{cm})\end{array}$ & $\begin{array}{l}\text { Standard deviation } \\
\text { between runs }(\mathrm{cm})\end{array}$ & $\begin{array}{l}\text { Angular error } \\
\text { (degrees) }\end{array}$ \\
\hline 0 & 0.059 & 0.008 & 0.008 \\
\hline 1.433 & -1.530 & 0.013 & 0.011 \\
\hline 2.866 & -2.992 & 0.035 & 0.029 \\
\hline 4.301 & -4.521 & 0.015 & 0.011 \\
\hline-4.301 & 4.543 & 0.005 & 0.007 \\
\hline-2.866 & 2.972 & 0.006 & 0.007 \\
\hline-1.433 & 1.426 & 0.005 & 0.006 \\
\hline \multicolumn{4}{|c|}{ Roll data (left-right) } \\
\hline Angle (degrees) & $\begin{array}{l}\text { Average actuator } \\
\text { position }(\mathrm{cm})\end{array}$ & $\begin{array}{l}\text { Standard deviation } \\
\text { between runs }(\mathrm{cm})\end{array}$ & $\begin{array}{l}\text { Angular error } \\
\text { (degrees) }\end{array}$ \\
\hline 0 & -0.007 & 0.004 & 0.015 \\
\hline 1.433 & -0.344 & 0.005 & 0.022 \\
\hline 2.866 & -0.688 & 0.005 & 0.019 \\
\hline 4.301 & -1.037 & 0.004 & 0.015 \\
\hline-4.301 & 1.038 & 0.008 & 0.033 \\
\hline-2.866 & 0.685 & 0.004 & 0.018 \\
\hline-1.433 & 0.343 & 0.005 & 0.019 \\
\hline
\end{tabular}

rections. After each attempted return, use of the sine bar and precision level helped remove any residual error in the table placement and thus returned the tabletop to the desired angle. The mean and standard deviation of the recorded actuator positions established the angular error (Table I).

A full range of motion has been achieved with a $115-\mathrm{kg}$ load fully extended at the head of the table. During static testing a $135-\mathrm{kg}$ load placed on the end of the table did no damage to the system. Dynamic testing with a $160-\mathrm{kg}$ load spread evenly over the length of the table showed no effect on overall precision, however, the inherent table deflection varied with load. The time required for movement from one setup to the next is a factor of the angular displacement and the acceleration and maximum velocity of the actuators. The acceleration and velocity were set with patient comfort in mind and resulted in setup times of less than $1.5 \mathrm{~s}$ per degree in tilt and less than $1 \mathrm{~s}$ per degree in roll. With a maximum repeatability error less than $\pm 0.03^{\circ}$, this system exceeded all design specifications.

These results indicate that the tilt and roll device meets the requirements necessary for use in a "target of the day" localization system. ${ }^{9}$ Integration of the TARS with a programmable controller to handle movement of the actuators allows the user to control speed, distance, velocity, and acceleration of the individual actuators through an RS-232C port or through a touch pad control interface. Software currently under development will integrate these tilt and roll correction capabilities into a semi-automated daily setup and localization system. ${ }^{1}$

\section{ACKNOWLEDGMENT}

Work supported by NIH Grant No. P01-CA59827.

${ }^{1}$ J. Balter, R. K. Ten Haken, and K. L. Lam, "'Treatment setup verification," in Teletherapy, Present and Future, edited by T. R. Mackie and J. R. Palta (Advanced Medical Publishing, Madison, WI, 1996), pp. 61-66. ${ }^{2}$ A. L. Boyer, L. E. Antonuk, A. Fenster et al., "A review of Portal Imaging Devices. (EPIDs)," Med. Phys. 19, 1-16 (1992).

${ }^{3}$ J. Balter, G. T. Y. Chen, and C. A. Pelizzari, "Correlation of projection radiographs in radiation therapy using open curve and point pairs," Med. Phys. 19, 329-334 (1992).

${ }^{4}$ J. E. Schewe, J. M. Balter, K. L. Lam, and R. K. Ten Haken, "Measurement of patient setup errors using port films and a computer-aided graphical alignment tool,"' Med. Dosim. 21 (1996).

${ }^{5}$ J. Balter, D. L. McShan, K. L. Lam, J. Kim, and R. K. Ten Haken, "Incorporation of patient setup measurement and adjustment within a computer-controlled radiotherapy system,"' in Proceedings of the XIIth International Conference on the use of Computers in Radiation TherapyICCRT, edited by G. Starkschall and D. D. Leavitt (Advanced Medical Publishing, Madison, WI, 1997).

${ }^{6}$ S. M. Morrill, M. Langer, and R. G. Lane, "Theoretical advantages to real-time linac couch control to compensate for organ motion," Med. Phys. 23, 1083 (1996) (abstract).

${ }^{7}$ K. L. Lam, D. C. Hornick, J. Balter, S. Emanuel, S. Kota, and R. K. Ten Haken, "Development of a tilt and roll table for automated correction of setup errors," Med. Phys. 22, 940 (1995) (abstract).

${ }^{8}$ J. Hanley, G. Mageras, J. Sun, and G. J. Kutcher, "The effects of out-ofplane rotations on two-dimensional portal image registration in conformal radiotherapy of the prostate,' Int. J. Radiat. Oncol., Biol., Phys. 33, 1331-1343 (1995).

${ }^{9}$ J. Balter, K. L. Lam, H. M. Sandler, F. J. Littles, R. L. Bree, and R. K. Ten Haken, "Automated localization of the prostate at the time of treatment using implanted radiopaque markers: Technical feasibility," Int. J. Radiat. Oncol., Biol., Phys. 33, 1281-1286 (1995). 